\title{
Measuring lexical access during sentence processing
}

\author{
MICHELLE A. BLANK \\ Bell Laboratories, Whippany, New Jersey 07981
}

\begin{abstract}
The results from "on-line" investigations of sentence comprehension are often difficult to interpret since it is not always apparent what component processes are reflected in the response measure. The results of two experiments reported here indicate that response latencies from phoneme-triggered lexical decision (PTLD) reflect the time needed for lexical access during sentence processing. Listeners were presented with sentences and were asked to make a word/nonword judgment for items beginning with a particular word-initial target phoneme. Speed of lexical access was manipulated by varying the semantic predictability of the targetbearing word. WORD judgments were faster for words that were preceded by semantically related verbs than were WORD judgments for words that were preceded by neutral verbs. The present results are consistent with other studies showing semantic facilitation of lexical access during the processing of fluent speech. It is argued that the phoneme-triggered lexicaldecision task is a more suitable measure of lexical access during sentence processing than phoneme monitoring (Foss, 1969) or word monitoring (Marslen-Wilson \& Tyler, 1975). In addition, it is pointed out that the phoneme-triggered lexical-decision task lends itself to modifications which should enable investigators to study various aspects of on-line sentence processing.
\end{abstract}

The problem of discovering how listeners understand spoken language is unquestionably a formidable one. A first step taken by psycholinguists toward solving this problem has been to view sentence comprehension in terms of several component processes. Presumably, these processes include at least an acoustic analysis of the incoming waveform, phonetic and phonological analyses, lexical look-up, as well as syntactic and semantic integration (see, e.g., Studdert-Kennedy, 1974). The results from a large number of studies suggest that these processes combine in such a way as to form a "dynamicinteractive" system (e.g., Foss \& Blank, 1980; MarslenWilson, 1975; Marslen-Wilson \& Welsh, 1978). In a system of this kind, computations being executed by each process are influenced by other ongoing analyses occurring at other processing levels.

A variety of tasks have been used to study the component processes of sentence comprehension. It would be unrealistic and beyond the scope of this paper to review each of these techniques. Instead, it suffices to say that they can be classified into one of two groups: those that reflect postsentence comprehension processes and those that reflect on-line processing. Because of the speed and apparent interactive nature of the subprocesses involved in understanding sentences, it appears that on-line measurements obtained during sentence comprehension are valuable tools for investigating

This article is based on a paper originally presented at the Southwestern Psychological Association, New Orleans, 1978. I thank my friends and colleagues Don Foss, Wendy Idson, Pam Holley-Wilcox, and Dave Pisoni for their time in reading this manuscript and their many helpful suggestions. I also thank John Morton for his criticisms. sentence processing. A few examples of tasks that have been assumed to reflect ongoing sentence processing include speech shadowing (e.g., Marslen-Wilson, 1973), phoneme-monitoring (e.g., Foss, 1969), word monitoring (e.g., Marslen-Wilson, 1975), and mispronunciation detection (e.g., Cole, 1973). It should be noted, however, that for many on-line techniques a complete specification of the perceptual processes involved in performing the task is not available. This is in no way a trivial point, given that task demands are known to affect the perceptual organization and encoding of stimuli (e.g., Aaronson, 1976; Ammon, Ostrowski, \& Alward, 1971; Carey, 1971). Thus, psycholinguists need not only tasks that measure immediate processing, but also knowledge about how such tasks interact with sentence processing mechanisms. Without an explicit set of assumptions about these interactions, it is difficult to accurately interpret reaction time data obtained using any of these techniques (see Foss \& Blank, 1980, for further discussion of this point).

The purpose of this paper is to introduce a new task which will hopefully be a useful addition to the psycholinguist's experimental arsenal of on-line measures of sentence processing. Moreover, an attempt will be made to specify at least some of the underlying processes involved in the task.

The new task, phoneme-triggered lexical decision (PTLD), is the result of combining two techniques, lexical decision and phoneme monitoring. These two tasks have been used in numerous psycholinguistic studies (e.g., Blank \& Foss, 1978; Forster \& Chambers, 1973; Foss, 1970; Foss \& Jenkins, 1973; Meyer, Schvaneveldt, \& Ruddy, 1975; Scarborough, Cortese, 
\& Scarborough, 1977). Before describing PTLD, a brief description of lexical decision and phoneme monitoring is needed.

In lexical decision experiments, subjects are presented with a series of individual words and nonwords and are asked to make a word/nonword judgment for each item. Response times are measured from the onset of the item to the execution of the response. Latencies are taken as a measure of lexical access. In phoneme monitoring, subjects listen to a list of individual sentences. Each sentence is preceded by the specification of a target phoneme. The subjects' task is to press a button when they hear the word-initial target phoneme specified for that sentence. Reaction times obtained using this task represent the time elapsed between the onset of the target phoneme and the subjects' response. These times are taken to reflect the relative complexity of comprehension or, more germane to the present discussion, of one or more of its component processes.

In the PTLD task, listeners are asked to make a word/ nonword judgment for a particular word occurring within a sentence. The word that listeners judge is the one that begins with the target sound specified for that sentence. Listeners indicate their responses by pressing one of two buttons labeled either "real word" or "nonsense word." Table 1 lists sample sentences that I have used in PTLD studies. Each sentence is preceded by the specified target phoneme for that sentence, and the correct response is indicated for the underlined target word. In short, listeners use the target phoneme to "trigger" their lexical decisions (i.e., their word/nonword judgments). Like phoneme monitoring, response times are measured from the onset of the target phoneme to the time one of the buttons is depressed. The pilot study and main experiment reported here bear on the question of whether or not PTLD can be used to investigate lexical access as it occurs during sentence comprehension.

At this point, a word is in order about the relationship between PTLD and phoneme monitoring. Phoneme monitoring has, in the past, been used with some success

Table 1

Example Sentences Used in Phoneme-Triggered Lexical Decision Studies

\begin{tabular}{clc}
\hline $\begin{array}{c}\text { Trigger } \\
\text { Phoneme }\end{array}$ & \multicolumn{1}{c}{ Sentence } & \multicolumn{1}{c}{$\begin{array}{c}\text { Correct } \\
\text { Response }\end{array}$} \\
\hline$/ p /$ & $\begin{array}{l}\text { Before going to bed, the trav- } \\
\text { eling salesman packed his } \\
\text { suitcase. }\end{array}$ & WORD \\
$/ \mathrm{t} / \mathrm{l}$ & $\begin{array}{l}\text { The famous surgeon skillfully } \\
\text { removed the tadgy bullet frag- } \\
\text { ments from the victims chest. }\end{array}$ & NONWORD \\
& $\begin{array}{l}\text { Within a matter of moments, } \\
\text { the tacreela destroyed all of } \\
\text { the homes along this side of } \\
\text { the street. }\end{array}$ & WORD \\
\hline
\end{tabular}

to investigate "on-line" lexical processing during sentence comprehension (e.g., Blank \& Foss, 1978; Foss \& Jenkins, 1973). What, then, is the important difference between these two tasks?

One of the assumptions underlying the interpretation of phoneme monitoring response times is that listeners respond to target phonemes by referencing an abstract sound representation of the target-bearing word. This information about a word's sound pattern is presumably stored in the mental lexicon along with the word's syntactic and semantic codes. All of this information becomes potentially available to a listener subsequent to word identification. Thus, the phonological code of a word is derived when its syntactic and semantic information has been accessed. A corollary assumption that follows from this view is that phoneme-monitoring latencies reflect the time needed to access the targetbearing word from the lexicon (Foss \& Swinney, 1973; Morton \& Long, 1976; Marslen-Wilson \& Tyler, Note 1). However, recent evidence suggests that listeners can use stimulus (that is, acoustic/phonetic) information to identify phonemes (Blank, 1979; Foss \& Blank, 1980; Newman \& Dell, 1978). For word-initial phonemes, this "sensory-based" information is derived independently of, and prior to, lexical access. Thus, it appears that phoneme monitoring response times may not always reflect recognition of the target-bearing word. Whenever a target phoneme is identified on the basis of stimulus information, a response could be initiated before lexical access. The proposal that subjects in phoneme monitoring experiments "can" or "might" identify phonemes on the basis of sensory information is not a new one (see Foss \& Lynch, 1969). However, this notion was subsequently abandoned in favor of the view that a phoneme is identified "on the basis of the internal response following recognition of the word containing it" (Morton \& Long, 1976, p. 43). Now that questions have been raised concerning the perceptual processes underlying phoneme monitoring, the interpretations of some earlier monitoring studies must be reconsidered.

In contrast to phoneme monitoring, the task demands of PTLD insure that responses will be executed after the target-bearing word has been accessed (i.e., postlexically). Although phoneme monitoring is one component of PTLD, it is a necessary, not sufficient, process for an appropriate response to be made. A lexical decision can never be made without consulting the lexicon. This is because listeners cannot know whether a given stimulus input corresponds to a real word or a nonsense word until lexical access is attempted. Only after lexical access can listeners determine if a given acoustic signal has a corresponding abstract sound representation stored in the lexicon with semantic and syntactic information associated with it. Thus, unlike phoneme monitoring, PTLD guarantees that lexical access has occurred prior to execution of the response. Consequently, PTLD latencies should provide on-line measures of lexical access. 


\section{PILOT STUDY}

A pilot study was conducted to simply test whether subjects could perform this task with relative ease and no adverse effects on comprehension. The materials used in this experiment were originally designed for a phoneme monitoring study reported by Foss and Blank (1980). However, by merely changing the instructions, these materials could be used to obtain information relevant to the present issue.

Eighteen experimental sentences were varied in the following manner: the target-bearing item was either a real word or a nonsense word. An example sentence, with $/ \mathrm{p} /$ as the triggering phoneme, is given below:

The inquisitive young investigator annoyed the (prominent/pradament) businessman on trial for misuse of funds.

Each subject heard 9 real-word sentences and 9 nonsense-word sentences; no subject heard both versions of the same experimental sentence. Eight subjects heard a total of 72 sentences (18 experimental/54 filler). Handedness was counterbalanced across word/nonword button positions. Subjects were forewarned in the instructions that after they heard all the sentences a comprehension test would follow. This instruction was intended to emphasize the importance of paying close attention to the meaning of the sentences. The comprehension test was actually a recognition task consisting of 24 sentences. Half of these sentences were old (the subjects had heard them during the experiment) and half were new. The subjects were instructed to state whether each sentence was old or new. All of the old sentences were chosen from among those fillers which contained only real English words. Only those subjects who made six or fewer errors on the comprehension test were included in this study.

The results of this pilot study were as follows: mean reaction time for word targets was $857 \mathrm{msec}$, whereas mean reaction time for nonsense word targets was $1,111 \mathrm{msec}$. These response times are in accord with a well-documented effect obtained in lexical-decision studies-longer latencies for nonwords than for words. This difference was significant by a sign test $(p<.01)$.

Since this study was not designed to test directly whether observed RTs reflected the process of searching the mental lexicon for an entry, no further statistical analyses were done on these data. The main problem with using the observed RT difference as a basis for inferring processing differences between words and nonwords is that word and nonword responses were not counterbalanced in this pilot study. A nonword response was the appropriate response for only one-fourth of the trials. Thus, subjects probably had a strong bias to respond WORD on any given trial. This does not undermine the important finding of this pilot-subjects can perform this task with relative ease and speed.
When subjects were asked if they felt that the word/ nonword judgment was difficult or if it interfered with their understanding of the sentences, the overwhelming response was no. An examination of subjects' performance on the comprehension test confirmed their intuitions. The percentage of subjects who passed the comprehension test in this experiment (that is, made six or fewer errors) was exactly comparable to the percentage obtained for subjects who, in another experiment (Foss \& Blank, 1980), heard the same tapes and were given the same comprehension test, but were given phoneme monitoring instructions.

It is noteworthy that in the Foss and Blank study phoneme monitoring reaction times to targets contained in real words were no faster than reaction times to targets contained in nonsense words. Foss and Blank point out that this finding calls into question the assumption that phoneme monitoring latencies always reflect lexical processing of the target-bearing word. In contrast, the results of the present pilot study suggest that PTLD can tap into lexical access at a point during sentence processing when phoneme monitoring cannot. That is, the task demands of PTLD appear to ensure lexical access. A stronger test of this claim follows.

\section{MAIN EXPERIMENT}

On the basis of the preliminary findings of the pilot study, a more rigorous investigation of the usefulness of PTLD as a measure of lexical access during sentence processing was carried out. It was decided that an appropriate test of the sensitivity of this task to lexical access would be to manipulate semantic context. Numerous studies have found that the identification of a word in a list is facilitated by the prior occurrence in the list of semantically related words (e.g., Fischler, 1977; Meyer \& Schvaneveldt, 1971). In addition, a few studies indicate that a similar effect can be observed in sentences. Blank and Foss (1978) have presented evidence suggesting that lexical access during sentence processing is facilitated by the prior occurrence of semantically related words within a sentence (see Cole \& Jakimik, 1979, for a similar finding). This result was replicated by Foss, Cirilo, and Blank (1979). Morton and Long (1976) have also argued that lexical access is faster when a biasing semantic context has occurred earlier within a sentence. In their study, the constraining semantic context typically could not be pinpointed to a specific word or two. Rather, it was the interpretation of the sentence fragment that seemed to affect lexical processing.

The main study reported here was designed to test the hypothesis that PTLD response times reflect the time needed for lexical access as it occurs during sentence processing. If this is the case, response times should be sensitive to the facilitation of this process by the prior occurrence of a semantic constraint. In order to test this hypothesis, the prior occurrence of a seman- 
tically related word was varied within a set of experimental sentences. In each sentence, the verb was either semantically biasing or neutral to the noun that served as its direct object. Hence, an experimental sentence had two versions which differed from each other by the occurrence (or nonoccurrence) of a semantically related word. In each of the experimental sentences, the direct object was the target word. Consequently, word/nonword judgments were triggered by the initial phoneme of the direct object. An example sentence is given below:

The student (headed/drove) the expensive car back into a tree when the instructor wasn't looking.

In this sentence, the target word is "car" and the triggering phoneme is $/ \mathrm{k} /$. If PTLD is sensitive to accessing the target word from the mental lexicon, then PTLD response times should reflect the facilitative effect of the semantically biasing word "drove" on the lexical processing of "car" relative to the effect of the neutral word "headed."

An important difference between this experiment and the pilot study is that the comparison of interest is not between responses to words and nonwords. Instead, responses to the experimental sentences are always WORD judgments and the important comparison is between WORD judgments for words preceded by a related verb and WORD judgments for words preceded by an unrelated verb. The function of the nonword judgments made on filler sentences is to make the task a sensible one for subjects to perform.

\section{Method}

Design and Materials. Twenty basic experimental sentences were constructed. Each sentence had two versions which defined the two experimental conditions: the verb was either semantically biasing or neutral to the direct object. Appendix 1 lists the 20 experimental sentences used in this study. In order for each of these sentences to occur in both conditions across the experiment, two material sets were constructed. Each set contained all 20 basic sentences; 10 of the sentences in both sets came from each of the two conditions. The experiment was therefore a 2 (verb context: biasing/neutral) by 2 (material sets) factorial design, with the former variable being within subjects and the latter being between subjects.

Thirteen of the semantically biased verb-noun pairs used in the experimental sentences were selected on the basis of relatedness ratings obtained from 127 undergraduate psychology students who did not participate in the main experiment. The subjects doing the rating were given a list of 100 simple sentences, all of the type: (Det) N V Det (Adj) N. In each sentence, either the verb or the adjective was underlined along with the direct object. The subjects' task was to judge how related the two underlined words were to each other. More specifically, subjects were asked to judge how often the first underlined word made them "think of" the second underlined word. Each subject made 50 verb-noun pair judgments and 50 adjectivenoun pair judgments. The subjects used a 5-point rating scale to indicate their judgments, where 1 represented $0 \%-20 \%$ of the time and 5 represented $80 \%-100 \%$ of the time. Only those verb-noun pairs for which the degree of relatedness of the verb to noun was judged to be between $70 \%-100 \%$ by a minimum of $75 \%$ of the subjects were used in the main experiment. The remaining seven semantically biased verb-noun pairs used in the experimental sentences were those which consistently elicited a particular noun as the response when presented to several colleagues for judgment. On the other hand, there was no agreement among noun responses when the neutral verbs were presented. The frequencies of the biasing and neutral verbs were matched according to Kučera and Francis (1967) estimates.

The initial structure of each experimental sentence was NP V Det Adj N... In these sentences, the direct object noun was always the target word; hence, word/nonword judgments were triggered by the initial phoneme of the direct object. Five stop consonants were used as targets among the experimental sentences with the following frequencies of occurrence: $/ \mathrm{b} /, 6 ; / \mathrm{p} /, 4 ; / \mathrm{d} /, 3 ; / \mathrm{t} /, 2 ; / \mathrm{k} /, 5$. Twenty filler sentences which had nonwords as the target "words" were constructed. That is, the target phoneme occurred on a nonword. Six stop consonants were used as targets among these "nonword" fillers with the following frequencies of occurrence: $/ \mathrm{b} /, 2 ; / \mathrm{p} /, 4 ; / \mathrm{d} /, 2 ; / \mathrm{t} /, 4$; $/ \mathrm{g} /, 4 ; / \mathrm{k} /, 4$. Ten additional fillers which did not contain a target word beginning with the specified target phoneme were constructed. Of these "nontarget" fillers, 5 contained a nonword. A final group of 10 fillers were constructed which had real words as the target word. Of these "real-word" fillers, one-half contained a nonword. Appendix 2 lists examples of the various types of filler sentences used in the experiment. The filler sentences were identical for both material sets. The total 60 sentences were randomized, with each basic experimental sentence occurring in the same position for the two sets of experimental materials.

A female speaker recorded the two material sets on one track of an audio tape. A pulse, inaudible to subjects, was placed on another track of the tape at the beginning of the initial phoneme of each target "word." The pulse started a timer which stopped when subjects pressed a button. Timing and data collection were controlled by a PDP-8/I computer.

Subjects. The subjects were 37 undergraduate psychology students at the University of Texas at Austin who participated in the experiment in partial fulfillment of a course requirement. Twenty subjects were assigned to one material set; 17 were assigned to the other.

Procedure. Subjects were tested in groups of one to six, with the experimenter and subject occupying adjoining rooms. Each subject was seated in a booth out of sight of the others.

Instructions describing the subjects' task were recorded at the beginning of each experimental tape. The instructions and the test sentences were presented binaurally over headphones. The subjects were told to lightly rest the index finger of each hand on the two response buttons in front of them. One button was labeled real word; the other was labeled nonsense word.

The subjects were informed that they were going to be presented with a list of sentences and that some sentences would contain a nonsense word and some sentences would contain only real English words. Their instructions were to press one of the buttons as quickly as possible when they heard a "word" in the sentence that began with a particular target sound (i.e., "buh as in Bob"). More specifically, the subjects were told to press the real word button if the word beginning with the target sound was a real word, and to press the nonsense word button if the word beginning with the target sound was a nonsense word. A trial consisted of the word "ready," specification of the target phoneme, and then presentation of a test sentence.

The subjects were also told that the target sound for those sentences that contained a nonsense word would not always occur on the nonsense word and that they should not allow the presence of a nonsense word to interfere with their task of pressing the appropriate button when they heard a word beginning with the target sound specified for that sentence. In addition, subjects were told that some sentences would not contain a "word" beginning with the target sound specified for that sentence. In these cases, neither button was to be pressed. The subjects were given four practice sentences: one contained a realword target in a sentence with only real English words; one was a sentence with a nonsense-word target; one contained a nonsense word, but the target was a real word; and one was a sentence 
with all real English words but without a target-bearing word.

Subjects were forewarned in the instructions that, sometimes, immediately after they had heard a sentence a yes/no question would be asked pertaining to that sentence. In addition, they were told that they would be able to answer correctly only if they had understood the sentence. The importance of paying close attention to the sentences was emphasized by the fact that listeners did not know beforehand which sentences in the list would be followed by a question. The subjects indicated their answers to the comprehension questions by circling either YES or NO on the appropriate line of a printed answer sheet. A total of 16 questions were presented. Appendix 3 presents two sentences that subjects were tested on along with the corresponding questions and correct answers. The same comprehension test was administered to all subjects. A fifth practice sentence was given which was followed by a comprehension question. After the experimenter answered questions clarifying any uncertainties regarding the instructions, the list of experimental and filler sentences was presented.

\section{Results}

The mean RTs for each subject in the two verbcontext conditions were computed. The results for both conditions are shown in Table 2. These reaction times have been truncated in the following way. A mean and standard deviation was computed for each subject and for each item in the experiment. If any individual RT was more than 2.5 standard deviations from both the mean for the subject and the mean for the item, it was omitted and replaced by a procedure suggested by Winer (1971). This procedure resulted in replacing about $2 \%$ of the data. Missing data points which resulted from failures to respond (about 5\%) were also filled in according to Winer's procedure. Appendix 1 presents the mean RTs for the semantically biasing and neutral versions of each experimental sentence.

An unequal $\mathrm{N}$ analysis of variance by subjects showed a significant main effect for the verb context $\left[F_{1}(1,35)\right.$ $=9.23, p<.004]$. The analysis of variance by items also showed a significant verb context effect $\left[\mathrm{F}_{2}(1,19)=\right.$ $5.07, p<.03]$. No other main effects or interactions were significant. Error rates for the two conditions were: related verb, .04; unrelated verb, .06. The results of a $t$ test for dependent samples indicated that these error rates did not differ significantly from each other $[t(36)=1.96, p>.05]$.

The mean number of errors per subject on the comprehension test was .51. The overall error rate for performance on the comprehension test was less than $3 \%$ ( $p<.001$ of obtaining this level of performance by

Table 2

Mean Reaction Times (msec) for Biasing/Neutral Verb Context Experiment

\begin{tabular}{cc}
\hline Biasing Verb & Neutral Verb \\
\hline 736 & 783 \\
\hline
\end{tabular}

Note-Responses to the experimental sentences were all WORD judgments.
EXPERIMENTAL SEMTENCE LATEMCIES

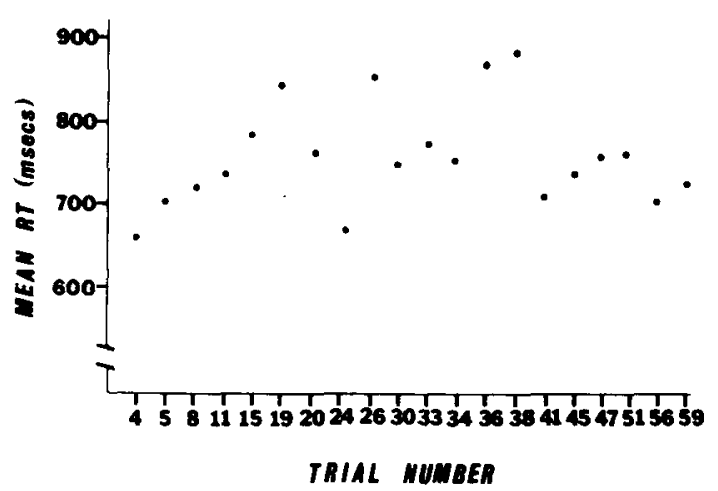

Figure 1. Experimental sentence latencies as a function of trial number.

chance). The small number of errors on the comprehension test suggests that listening for a particular wordinitial sound and making a lexical decision during sentence processing does not interfere with comprehension per se.

Figure 1 shows mean reaction times for the 20 experimental sentences as a function of trial number. There appear to be no systematic practice effects. Although there is an initial increase in response times, latencies do not remain at about $850 \mathrm{msec}$. Instead, they seem to fluctuate randomly between 670 and $900 \mathrm{msec}$. The fact that reaction times do not demonstrate a trend of any kind over trials suggests that subjects are not adopting unusual processing strategies as they become more familiar with the task.

\section{DISCUSSION}

The finding that word judgments for words were faster when they were preceded by a semantically related verb than by an unrelated verb supports the hypothesis that PTLD response times reflect on-line lexical processing during sentence comprehension. The basis for this conclusion will, perhaps, be more readily apparent after a brief consideration of the task demands of PTLD in conjunction with a slightly modified version of Morton's (1969) proposed model of word recognition.

According to Morton's model, each entry in the mental lexicon (or logogen) has associated with it a threshold value which defines the amount of information which must be received for the logogen to output its defining abstract sound representation (i.e., its phonological code). Once a logogen reaches its threshold level of activation, listeners gain access to this stored sound information. Interestingly, Morton does not assign semantic or syntactic information to logogens. He proposes that information of this kind, unlike phonological information, is accessed from the cognitive system rather than from the logogen system (see, e.g., 
Morton, 1979). It is this aspect of Morton's model that is modified here. For present purposes, logogens will be viewed as internal representations of words with syntactic and semantic defining characteristics as well as phonological attributes. According to this version of the model, when a logogen reaches its threshold value of activation it outputs all of the information associated with that device. In particular, syntactic, semantic, and phonological codes are produced. Both sensory and semantic information are accepted as input to the logogen system. These two types of information combine to activate logogens in such a way that there is a tradeoff relationship between them. More specifically, when a logogen receives semantic input from prior relevant context, there is a decrease in the amount of sensory information that is needed to bring it above its threshold.

If we now consider the task demands of PTLD, we will see why PTLD response times should provide a measure of lexical access. In order for listeners to make a WORD response in this task, two kinds of information must be available to them. On the one hand, they must have information about the identity of phoneme segments. That is, they need to know that they have heard the triggering sound. On the other hand, listeners must be able to assign a semantic interpretation to the item being judged. Given the framework of the logogen model just outlined, PTLD responses should be sensitive to lexical processing, since the phonological and semantic representations that are stored in the lexicon presumably become available only when a word's corresponding logogen is activated above threshold.

The results of the verb-context experiment are easily interpretable in accordance with the modified view of Morton's logogen model, which assigns syntactic, semantic, and phonological output codes to logogens. Simply stated, the spoken waveform corresponding to a target word required less sensory processing when it was preceded by a semantically related verb than when it was preceded by an unrelated verb. Presumably, this is because the logogen corresponding to the target word had been partially activated by the contextual information provided by the previously accessed semantically related verb. One way for semantically related words to partially activate logogens is by spreading semantic excitation among related lexical concepts in the mental lexicon (see, e.g., Collins \& Loftus, 1975). The finding of semantic facilitation in this study is consistent with two earlier phoneme monitoring studies showing context effects on word recognition during sentence processing (Blank \& Foss, 1978; Morton \& Long, 1976). Since PTLD response times are sensitive to the facilitative effects of semantic constraints on lexical processing, it seems reasonable to conclude that this measure indeed reflects lexical access as it occurs during sentence comprehension.

If investigators are interested in studying the effects of various factors on lexical access during sentence processing, it is imperative that they have an understanding of the sensitivities and limitations of their measurement techniques. Unlike phoneme monitoring, the task demands of phoneme-triggered lexical decision guarantee that a target-bearing word will be lexically processed prior to execution of the response. Phoneme. monitoring latencies may provide inaccurate measures of lexical access, since the phoneme monitoring task does not ensure processing at this level-responses are sometimes initiated before lexical access has occurred.

Similar criticisms may also be relevant in evaluating the merits of the "word-monitoring" task (e.g., MarslenWilson \& Tyler, 1975) as an on-line measure of lexical access during sentence processing. In particular, it may be that the task specifications of word monitoring introduce contextual factors which confound the time needed for lexical access. We know that the prior occurrence of a semantically related word affects speed of lexical access. Accordingly, it is more than likely that the prior occurrence of the exact word (as the target specification) in word monitoring will affect the ultimate processing of the target word. If this is the case, it is important that such effects be taken into account in interpreting word-monitoring response times. A systematic investigation of phoneme-triggered lexical decision, phoneme monitoring, and word monitoring as measures of lexical access during sentence processing is currently under way.

One final point should be made before summarizing. The PTLD task lends itself to slight modifications which may allow component processes other than lexical access to be measured during sentence comprehension. By simply changing the nature of the judgment triggered by the target phoneme, one may be able to tap directly into, say, inferential processes. The "on-line" construction of inferences could be investigated by having subjects make decisions that would require the making of an inference. Essentially, this task could be used to trigger virtually any type of judgment during sentence processing. Moreover, by changing the location of the target within a sentence, one could study the time course of these subprocesses. However, when using this or any other type of judgment task, the following two factors should always be considered: first, the relationship between the kind of judgment being made and the comprehension process; second, the inherent difficulty of the judgment being made. These two factors determine how the task demands might interact with sentence processing mechanisms, and this, in turn, affects the possible conclusions that can be drawn from the observed results.

To summarize, a new on-line measure of lexical access during sentence processing has been proposed. The results of the present PTLD verb-context study provides additional support for the facilitative effects of semantic constraints on word recognition in fluent speech. 


\section{APPENDIX 1}

Experimental Sentences Used in Verb Contexı Study

\begin{tabular}{|c|c|c|c|c|c|}
\hline \multicolumn{4}{|c|}{ Mean RT (msec) } & \multicolumn{2}{|c|}{ Mean RT (msec) } \\
\hline & Neutral & Biased & & Neutral & Biased \\
\hline \multirow{3}{*}{$\begin{array}{l}\text { The doctor chose to (hypnotize/hospitalize) } \\
\text { his new patient in order to find out the } \\
\text { cause of his discomfort. } \\
\text { The deranged physicist (rigged/detonated) } \\
\text { the dangerous bomb, causing widespread } \\
\text { havoc. }\end{array}$} & 724 & 609 & $\begin{array}{l}\text { The war veteran became (wary of/addicted } \\
\text { to) the illegal drug while he was in the army. }\end{array}$ & 757 & 779 \\
\hline & 779 & 653 & $\begin{array}{l}\text { The nurse (comforted/diapered) the finicky } \\
\text { baby after administering the injection. }\end{array}$ & 780 & 626 \\
\hline & & & $\begin{array}{l}\text { The security guard (protected/locked) the } \\
\text { front door every night. }\end{array}$ & 775 & 807 \\
\hline $\begin{array}{l}\text { The camper (craved/toasted) the packaged } \\
\text { bread that his mother gave him on visiting } \\
\text { day. }\end{array}$ & 795 & 879 & $\begin{array}{l}\text { The young girl (purchased/drank) the cold } \\
\text { beverage to quench her thirst. }\end{array}$ & 770 & 715 \\
\hline $\begin{array}{l}\text { The engineer (investigated/solved) the } \\
\text { difficult problem with his co-workers. }\end{array}$ & 712 & 691 & $\begin{array}{l}\text { A few amateurs (supervised/choreographed) } \\
\text { the modern dance that opened last night. }\end{array}$ & 703 & 732 \\
\hline \multirow{2}{*}{$\begin{array}{l}\text { The little boy (clasped/dialed) the kitchen } \\
\text { telephone even though his mother warned } \\
\text { him against it. }\end{array}$} & 860 & 820 & $\begin{array}{l}\text { The girls (inspected/iced) the special cake } \\
\text { they were bringing to the picnic. }\end{array}$ & 805 & 599 \\
\hline & & & $\begin{array}{l}\text { The maid (labelled/ironed) Peter's summer } \\
\text { clothes before packing them in his trunk. }\end{array}$ & 888 & 898 \\
\hline $\begin{array}{l}\text { The gunman (commandeered/skyjacked) } \\
\text { the commercial plane destined for Cuba. }\end{array}$ & 670 & 675 & $\begin{array}{l}\text { John's partner (grabbed/dealt) the yellow- } \\
\text { ing cards when it was his turn. }\end{array}$ & 826 & 700 \\
\hline $\begin{array}{l}\text { The student (headed/drove) the expensive } \\
\text { car back into a tree when the instructor } \\
\text { wasn't looking. }\end{array}$ & 890 & 633 & $\begin{array}{l}\text { The young athlete (hurled/pitched) the } \\
\text { soiled baseball into the strike zone. }\end{array}$ & 808 & 736 \\
\hline $\begin{array}{l}\text { The housekeeper (misplaced/watered) the } \\
\text { multicolored plant belonging to her } \\
\text { employer. }\end{array}$ & 804 & 756 & $\begin{array}{l}\text { The assistant (discounted/graded)the } \\
\text { difficult test because the professor requested } \\
\text { he do so. }\end{array}$ & 734 & 770 \\
\hline $\begin{array}{l}\text { employer. } \\
\text { The professor (finished/published) his } \\
\text { controversial book during the spring. }\end{array}$ & 711 & 752 & $\begin{array}{l}\text { The young police officer (investigated/ } \\
\text { arrested) the tough criminal despite threats } \\
\text { on his life. }\end{array}$ & 860 & 895 \\
\hline
\end{tabular}

APPENDIX 2

Example Filler Sentences Used in Verb Context Study

\begin{tabular}{llll}
\multicolumn{1}{c}{ Filler Type } & $\begin{array}{c}\text { Trigger } \\
\text { Phoneme }\end{array}$ & Sentence & $\begin{array}{c}\text { Correct } \\
\text { Response }\end{array}$ \\
\hline Nonword Target & $/ \mathrm{b} /$ & $\begin{array}{l}\text { The girls finally decided to throw out the brebben clock since it } \\
\text { was obviously not worth repairing. }\end{array}$ & NONWORD \\
$\begin{array}{l}\text { Word Target } \\
\text { (with nonword) }\end{array}$ & $/ \mathrm{d}$ After entering the tournament the golfer broke his dezzer and & WORD \\
$\begin{array}{l}\text { Word Target } \\
\text { withdrew from the competition. } \\
\text { Nontarget } \\
\text { with nonword) }\end{array}$ & $/ \mathrm{p} /$ & The man in the restaurant ordered a large frezmon for dinner. & NONE \\
Nontarget & $/ \mathrm{d} /$ & Yesterday afternoon a U.F.O. was sighted over New York City. & NONE \\
\hline
\end{tabular}

\section{APPENDIX 3}

(1) Sentence: All the major networks covered the lunar bouving yesterday afternoon.

Question: Was yesterday's event of national interest?
(2) Sentence: After hearing all the testimony, the jury found the defendant not guilty.

Question: Should the defendant be imprisoned? 


\section{REFERENCE NOTE}

1. Marslen-Wilson, W. D., \& Tyler, L. K. The temporal structure of spoken language understanding. Manuscript submitted for publication.

\section{REFERENCES}

Aaronson, D. Performance theories of sentence coding: Some qualitative observations. Journal of Experimental Psychology: Human Perception and Performance, 1976, 2, $42-55$.

Ammon, P. R., Ostrowski, B., \& Alward, K. Effects of task on the perceptual organization of sentences. Perception \& Psychophysics, 1971, 10, 361-363.

BLANK, M. A. Dual-mode processing of phonemes in fluent speech. Unpublished doctoral dissertation, University of Texas at Austin, 1979.

Blank, M. A., \& Foss, D. J. Semantic facilitation and lexical access during sentence processing. Memory \& Cognition, 1978, 6, 644-652.

Carey, P. W. Verbal retention after shadowing and after listening. Perception \& Psychophysics, 1971, 9, 79-83.

Cole, R. A. Listening for mispronunciations: A measure of what we hear during speech. Perception \& Psychophysics, 1973, 3, 153-156.

Cole, R. A., \& Jакıмıк, J. Understanding speech: How words are heard. In G. Underwood (Ed.), Information processing strategies. New York: Academic Press, 1979.

Collins, A. M., \& Loftus, E. F. A spreading-activation theory of semantic processing. Psychological Review, 1975, 82, 407-428.

Fischler, I. Semantic facilitation without association in a lexical decision task. Memory \& Cognition, 1977, 5, 335-339.

Forster, K. I., \& Chambers, S. M. Lexical access and naming time. Journal of Verbal Learning and Verbal Behavior, 1973, 12, 627-635.

Foss, D. J. Decision processes during sentence comprehension: Effects of lexical item difficulty and position upon decision times. Journal of Verbat Learning and Verbal Behavior, 1969 , $8,457-462$.

Foss, D. J. Some effects of ambiguity upon sentence comprehension. Journal of Verbal Learning and Verbal Behavior, 1970, 9, 699-706.

Foss, D. J., \& Blank, M. A. Identifying the speech codes. Cognitive Psychology, 1980, 12, 1-31.

Foss, D. J., Cirilo, R. K., \& Blank, M. A. Semantic facilitation and lexical access during sentence processing: An investigation of individual differences. Memory \& Cognition, 1979, 7, 346-353.

Foss, D. J., \& Jenkins, C. M. Some effects of context on the comprehension of ambiguous sentences. Journal of Verbal Learning and Verbal Behavior, 1973, 12, 577-589.

Foss, D. J., \& LynCH, R. H., JR. Decision processes during sen- tence comprehension: Effects of surface structure on decision times. Perception \& Psychophysics, 1969, 5, 145-148.

Foss, D. J., \& Swinney, D. A. On the psychological reality of the phoneme: Perception, identification, and consciousness. Journal of Verbal Learning and Verbal Behavior, 1973, 12, 246-257.

KuČera, H., \& Francis, W. N. Computational analysis of present day American English. Providence, R.I: Brown University Press, 1967.

Marslen-Wilson, W. D. Linguistic structure and speech shadowing at very short latencies. Nature, 1973, 244, 522-523.

Marslen-Wilson, W. D. Sentence perception as an interactive parallel process. Science, 1975, 189, 226-227.

Marslen-Wilson, W., \& Tyler, L. K. Processing structure of sentence perception. Nature, 1975, 257, 784-785.

Marslen-Wilson, W. D., \& Welsh, A. Processing interactions and lexical access during word recognition in continuous speech. Cognitive Psychology, 1978, 10, 29-63.

Meyer, D. E., \& Schvaneveldt, R. W. Facilitation in recognizing pairs of words: Evidence of a dependence between retrieval operations. Journal of Experimental Psychology, 1971, 90, 227-234.

Meyer, D. E., Schvaneveldt, R. W., \& Ruddy, M. G. Loci of contextual effects in visual word recognition. In P. M. A. Rabbitt \& S. Dornic (Eds.), Attention and performance $V$. London: Academic Press, 1975.

Morton, J. Interaction of information in word recognition. Psychological Review, 1969, 76, 165-178.

Morton, J. Facilitation in word recognition: Experiments causing change in the logogen model. In P. A. Kolers, M. E. Wrolstal, \& H. Bouma (Eds.), Proceedings of the Conference on the Processing of Visible Language. New York: Plenum, 1979.

Morton, J., \& LoNG, J. Effect of word transitional probability on phoneme identification. Journal of Verbal Learning and Verbal Behavior, 1976, 15, 43-52.

Newman, J. E., \& Dell, G. S. The phonological nature of phoneme monitoring: A critique of some ambiguity studies. Journal of Verbal Learning and Verbal Behavior, 1978, 17, 359-374.

Scarborough, D. L., Cortese, C., \& Scarborough, H. S. Frequency and repetition effects in lexical memory. Journal of Experimental Psychology: Human Perception and Performance, 1977, 3, 1-17.

Studdert-Kennedy, M. The perception of speech. In T. A. Sebeok (Ed.), Current trends in linguistics (Vol. 7). The Hague: Mouton, 1974.

Winer, B. J. Statistical principles in experimental design. New York: McGraw-Hill, 1971.

(Received for publication December 10, 1979; revision accepted March 18, 1980.) 